\title{
Thermodynamic study on the mechanism of carbonic anhydrase XII inhibition with glycosyl coumarin as non-zinc mediated inhibitors: A quantum mechanical investigation
}

\author{
Mina Ghiasi *, Mina Seifi \\ Department of Chemistry, Faculty of Physics E Chemistry, Alzahra University, 19835-389 Vanak, Tehran, Iran
}

\section{A R T I C L E I N F O}

\section{Article history:}

Received 19 June 2017

Received in revised form 30 August 2017

Accepted 31 August 2017

Available online 1 September 2017

\section{Keywords:}

Carbonic anhydrase

Glycosyl coumarin

Inhibition mechanism

QM calculation

\begin{abstract}
A B S T R A C T
In the present study, experimentally observed inhibition mechanism of zinc enzyme carbonic anhydrase XII (CA XII) by new class of suicide inhibitors, glycosyl coumarin, has been modeled using of density functional theory (DFT) to investigte the geometrical parameters and thermocemical aspects of this mechanism in the solution phase. In the first step of this research the most stable conformer of four 7-substituted sugar coumarin including galactose, mannose, ribose and glucose derivatives as more effective and coumarin as the less effective inhibitor of CA XII respectively has been search and interact with CA XII active site. The results of our calculations indicate that all above mentioned inhibitors do not directly interact with the metal ion from the CA active center. Moreover, the calculated thermodynamic function values indicate the presence of sugar moiety in the coumarin molecule was associated with more effective inhibition. Furthermore, interactions between the most stable conformer of galactose derivative as the best inhibitors with CA XII in presence of water solvent were studied by employing explicit solvent model. In addition the good agreements between our calculated results with experimental data indicate a reliable agreement of method of calculations.
\end{abstract}

(c) 2017 Elsevier B.V. All rights reserved.

\section{Introduction}

Metalloenzyme carbonic anhydrases (CAs, EC 4.2.1.1) [1] present in prokaryotes and eukaryotes which is encoded by three distinct gene families: (i) $\alpha$-CA (in vertebrates, bacteria, algae and cytoplasm of green plants), (ii) $\beta$-CA (in bacteria, algae and chloroplasts of mono- and dicotyledons) and (iii) $\gamma$-CAs (in archaea and some bacteria) [2-7]. In higher vertebrates, including humans, 14 different $\alpha$-CA isoforms have been isolated, where in these zinc enzymes play crucial physiological roles. Some of these isozymes are cytosolic (CA I, CA II, CA III and CA VII), others are membrane bound (CA IV, CA IX, CA XII and CA XIV), one is mitochondrial $(\mathrm{CA} \mathrm{V})$ and one is secreted in the saliva (CA VI). These enzymes are very efficient catalysts for the simple physiological reaction, including interconversion of the carbon dioxide and bicarbonate ion, thus are involved in crucial physiological processes connected with respiration and transport of carbon dioxide/bicarbonate between metabolizing tissue and lungs, electrolyte secretion in different organs and tissues, $\mathrm{PH}$ and $\mathrm{CO}_{2}$ homeostasis, biosynthetic reactions, calcification, bone resorption, tumorigenicity and many

\footnotetext{
* Corresponding author.

E-mail address: ghiasi@alzahra.ac.ir (M. Ghiasi).
}

physiological or pathological processes [6,7]. Moreover, $\alpha$-CA isoforms possess a high versatility, being able to catalyze other different hydrolytic processes, such as the hydration of cyanate or carbamic acid; hydrolysis of carboxylic or sulfonic acids ester; aldehyde hydration to gem-diols [6-8]. It is noticeable that many of these isozymes are special targets for the design of inhibitors with clinical applications. CAs are inhibited with several different compound such as metal complexing anion, sulfonamides, sulfamides, phenols and poly amines that bind to the metal ion through the enzyme active center or are anchored to the water molecule coordinated to the metal ion [1,9-11]. These kind of inhibitors act as potent inhibitors of CA I and II which playing important physiological roles [12-17]. Therefore the important barriers to the use of carbonic anhydrase inhibitors as therapeutic compounds are related to the various number of CA isoforms in human that localize in different tissues and organs.

In recent years a novel group of inhibitors of CA that belong to the new chemotype molecules including coumarins and their derivatives have been reported [18-20] that inhibit CA isoforms IX, XII, and XIII, Fig. 1. This new class of carbonic anhydrase inhibitors binds to the entrance of active form of the CA active center (hydrolyzed form) and does not directly interact with the metal ion such as presently available inhibitors of the sulfonamide and 


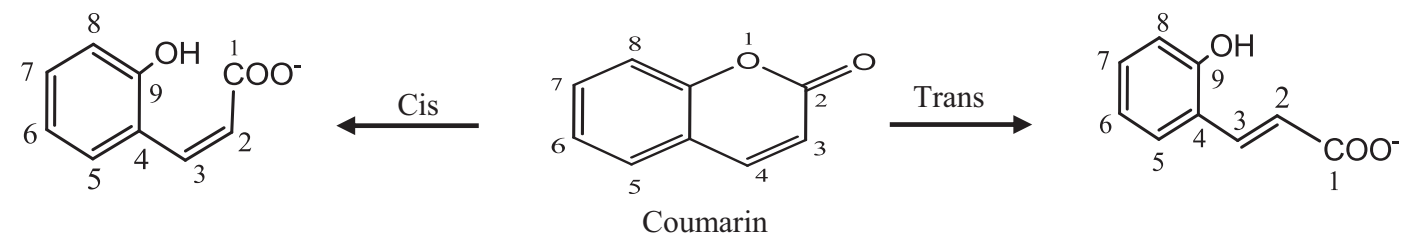

Fig. 1. Presentation of coumarin molecule and its hydrolysis product, cis- and trans-2-hydroxycinnamic acid with numbering for key atoms.

sulfamate type [19]. Scheme 1 presents the proposed inhibition mechanism of CAs by coumarin. According to Scheme 1, the first step of inhibition mechanism by coumarin and its derivatives is including the hydrolytic attack of the zink hydroxide species of the enzyme to the coumarin bound in its neighborhood within the enzyme active center. The cis-2-hydroxy-cinnamic acid can be stabilized toward the exit of the active site cavity. Alternatively, this intermediate isomerizes to the trans isomer which binds in the same active site region.
According to previous study the presence of sugar moieties in glycosidic sulfonamide carbonic anhydrase inhibitors show more effective inhibition of different isoforms such as CA IX and XII $[21,22]$. Moreover these new inhibitors show primary tumor growth inhibitory effects in a mouse breast cancer model [23]. Also CA XII is present in many tumor types with an extracellular active center which involved in many pathologic and physiologic processes and it is the most prone to inhibition by glycosylcoumarin [23].<smiles>Cc1cc(=O)oc2cc(OC3OC[C@H](O)[C@@H](O)[C@H](O)O3)ccc12</smiles><smiles>Cc1cc([O-])[o+]c2cc(OC3OC(O)[C@@H](O)[C@H](O)[C@H]3O)ccc12</smiles>

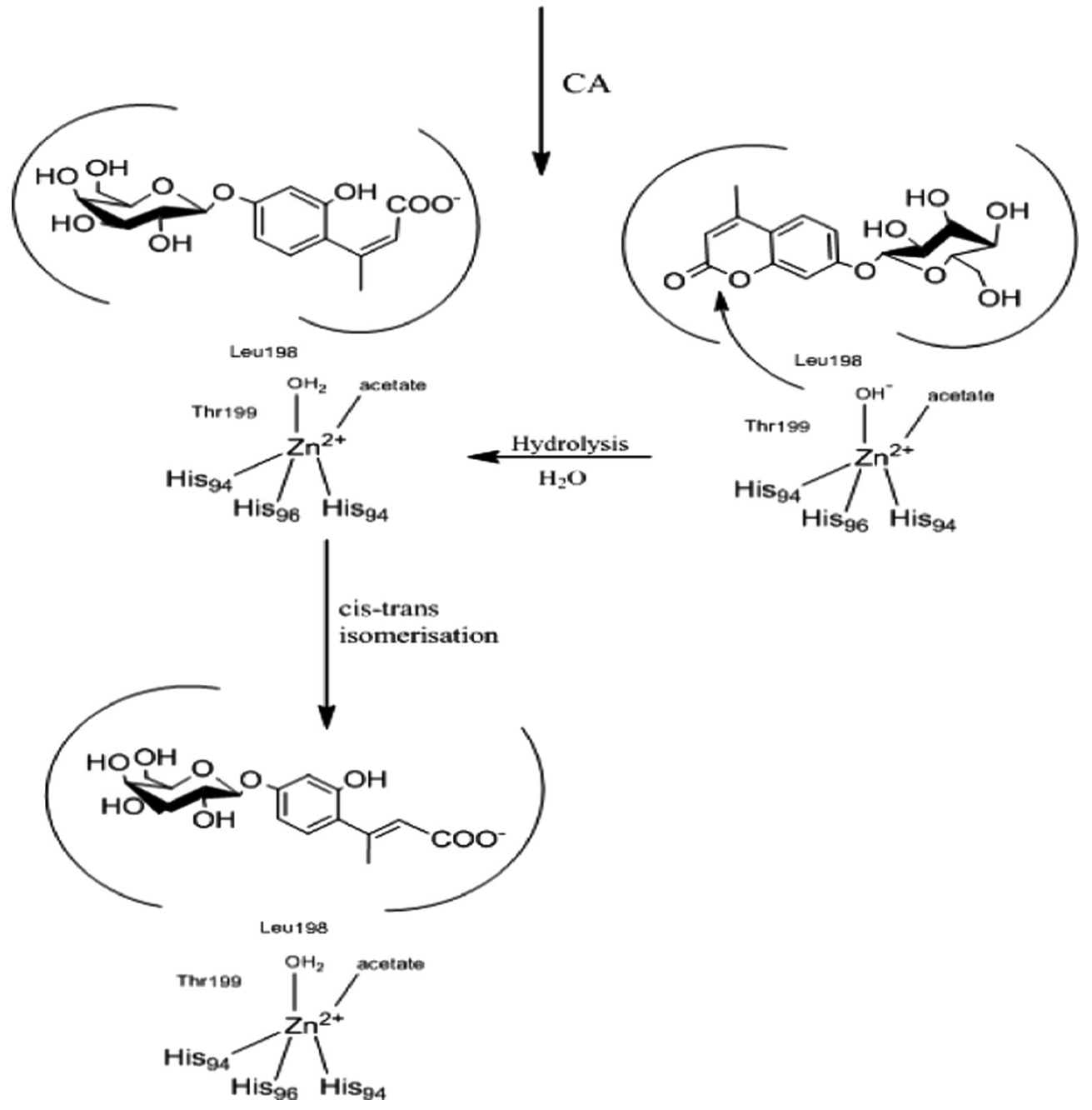

Scheme 1. Proposed inhibition mechanism of CA by coumarin that leading to cis/trans-2-hydroxy cinnamic acid. 
So in the present research we use the quantum mechanical calculations to investigate on the inhibition mechanism of 7substituted coumarins, Fig. 2, as potent inhibitor of CA XII [23] from thermodynamic point of view. Also to qualify the role of glycosyl moiety in inhibitor activity we study the inhibition mechanism of coumarin molecule with CA XII. The interesting point of sugar containing carbonic anhydrase inhibitors is related to this fact that these compounds show good water solubility. These results may bring novel insights into the design of new carbonic anhydrase inhibitors (CAIs).

\section{Computational scheme}

\subsection{Ab initio calculations}

The DFT computational study of active and inactive form of carbonic anhydrase XII enzyme active site with around amino acids and five inhibitors by determining the ground state geometries of all compounds without any symmetry constrains have been carried out. It is noticeable that amino acid residues were included in the DFT model are His-94, His-96, His-119, Thr-199 and Leu198, Fig. 3. All the calculations were performed at two levels of DFT methods to the performance of these two methods in prediction of geometry parameters and energy: (1) 6-31G* basis set using the B3LYP level of theory that consists of a Becke-Hartree-Fock exchange with Lee-Yang-Parr correlation functional with nonlocal corrections $[24,25]$. It has been shown that the use of B3LYP/6$31 \mathrm{G} *$ method in this kind of compounds predict reliable results which is in good agreement with experimental results $[8,15,26$ 28]; (2) 6-31 + G* basis set with M06 functional which has been reported as a hybrid meta-GGA (generalized gradient approximation) exchange correction functional which has been parameterized for transition metals and was proposed to study in organometallic and inorganometallic thermochemistry, kinetic and non-covalent interaction [29]. The harmonic vibrational frequencies were computed to confirm that an optimized geometry correctly corresponds to a local minimum that has only real frequencies. In addition, the vibrational frequencies have been employed to obtain enthalpies and Gibbs energies at $298.15 \mathrm{~K}$ and 1.0 atmosphere pressure. All reported enthalpies were zeropoint (ZPE) corrected with unscaled frequencies.

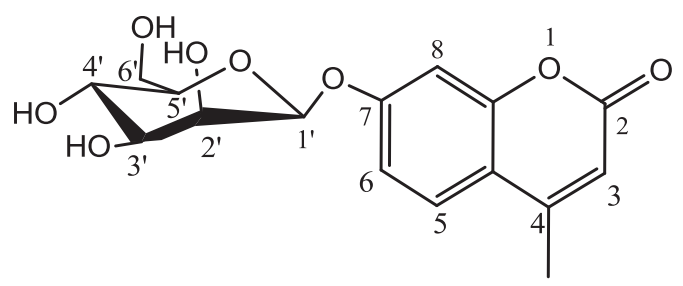

Mannose Coumarin

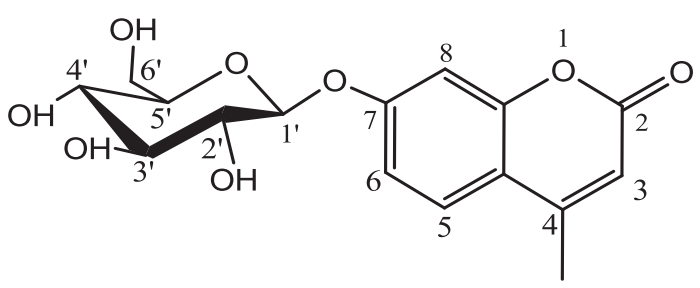

Glucose Coumarin
Potential energy surface of glycosyl coumarin are calculated in relation to the torsion angles $\omega, \theta$ and $\varphi$ defined by the $\mathrm{O} 5-\mathrm{C} 5-\mathrm{C} 6-\mathrm{O} 6, \mathrm{C} 5-\mathrm{C} 6-\mathrm{O} 6-\mathrm{H}$ and $\mathrm{H} 1-\mathrm{C} 1-\mathrm{O}-\mathrm{C}$ atoms respectively in sugar moiety. The torsion angles $\omega, \theta$ and $\varphi$ were scanned in step $5^{\circ}$ without any constrains on all other geometrical parameters. Afterward, the geometries were optimized without any restriction around each potential minimum. The solvent effect on the conformational equilibrium and contribution to the total enthalpies were investigated with PCM method [30]. Solvation calculations were carried out for water with the geometries optimization for this solvent. The PCM method shows good accuracy, reliability, adaptability and more reduced computational effort to describe solvent effect [31-33].

Moreover, the explicit solvent effect has been considered as well as an implicit solvent model. Finally, some single point calculations were also carried out with B3LYP/6-311++G** and M06/6$311++G * *$ method to provide a check on the B3LYP/6-31G* method.

All calculations were performed using the Gaussian 2009 software [34] and the GaussView program for visualization [35].

\subsection{Calculation of thermodynamic functions}

Since no experimental data of thermodynamic functions such as standard enthalpies of reaction $\left(\Delta \mathrm{H}^{\circ}{ }_{\text {rxn }}\right)$ and the standard Gibbs energies of reaction $\left(\Delta \mathrm{G}^{\circ}{ }_{\mathrm{rxn}}\right)$ is available; So $\Delta \mathrm{U}^{\circ}{ }_{\mathrm{rxn}}, \Delta \mathrm{H}_{\mathrm{rxn}}^{\circ}$, $\Delta \mathrm{S}^{\circ}{ }_{\text {rxn }}$ and $\Delta \mathrm{G}^{\circ}{ }_{\text {rxn }}$ was evaluated in the solution.

Total enthalpies of the studied species $\mathrm{X}, \mathrm{H}(\mathrm{X})$, at the temperature $\mathrm{T}$ are usually estimated from the Eq. (1) [36-38].

$$
\mathrm{H}(\mathrm{X})=\mathrm{E}_{0}+\mathrm{ZPE}+\mathrm{E}_{\text {trans }}+\mathrm{E}_{\mathrm{rot}}+\mathrm{E}_{\mathrm{vib}}+R T
$$

where $E_{0}$ is the calculated total electronic energy, ZEP stands for zero-point energy, $E_{\text {trans, }} E_{\text {rot }}, E_{\text {vib }}$ are the translational, rotational, and vibrational contributions to the enthalpy, respectively. Finally, RT represents PV-work term and is added to convert the energy to enthalpy.

The standard enthalpy change of the reaction $\left(\Delta \mathrm{H}^{\circ} \mathrm{r}\right)$ is given as:

$\Delta \mathrm{H}_{\mathrm{r}}^{\circ}=\left[\mathrm{H}_{\text {product }}^{\circ}\right]-\left[\mathrm{H}_{\text {reactant }}\right]^{\circ}$

Which total standard enthalpies of the studied species, at the temperature $\mathrm{T}$ estimated from the expression (1).

Fig. 2. Presentation of 7-glycosyl-4-methyl coumarin as the effective inhibitor of CAXII with numbering for key atoms. 
Similarity, $\Delta \mathrm{S}_{\mathrm{r}}^{\circ}$ could be obtained by

$\Delta \mathrm{S}_{\mathrm{r}}^{\circ}=\left[\mathrm{S}_{\text {product }}^{\circ}\right]-\left[\mathrm{S}_{\text {reactant }}\right]$

According to thermodynamic equation, $\Delta \mathrm{G}=\Delta \mathrm{H}-\mathrm{T} \Delta \mathrm{S}$, the $\Delta \mathrm{G}_{\mathrm{r}}^{\circ}$ was calculated.

\section{Results and discussion}

3.1. Geometry optimization of active and inactive form of carbonic anhydrase XII active center

The model system has been used here is assembled by using of the crystallographic structure available in literature, with PDB code: $1 \mathrm{jcz}$, [39]. According to X-ray data the native CAXII structure showing the five coordinate zinc ion. This model is included a zinc cation is located at the bottom of the conical active center which is bonded to $\mathrm{H}_{2} \mathrm{O}$ (in inactive form) or $\mathrm{OH}^{-}$(in active form) group, three imidazole rings belonging to the three histidine residues His-94, His-96 and His-119 and an acetate anion which is generating distorted trigonal bipyramid geometry of the $\mathrm{Zn}$ (II) ion, Fig. 3. It is noticeable that one oxygen atom of the acetate anion coordinates to zinc and the second oxygen atom accepts hydrogen bonds from the water molecule that is bonds to zinc and the backbone $\mathrm{NH}$ of Thr-199.

Structure of active form of carbonic anhydrase XII (ACAXII) and inactive form (ICAXII) was fully optimized at B3LYP/6-31G* and M06/6-31 + G* methods with no initial symmetry restrictions. Fig. 3 shows the optimized structure and some structural details of ACAXII and ICAXII in the gas phase. The average distance using the B3LYP and M06 methods between $\mathrm{Zn}^{2+}$ and $\mathrm{N}$ atom in histidine is $1.97 \AA$ that is in good agreement with X-ray crystallography data, $2.06 \AA$ A. Comparison between theoretical and X-ray [39] data indicates that the standard deviation of bond distances, for the B3LYP/6-31G* is less than M06/6-31 + G*, Table 1 . In continue the fully optimized geometries in gas phase re-optimized by considering the solvent effect using PCM method in water solvent. The calculated results indicate that the active and inactive form of CA XII is stabilized by about 29.43 and $57.05 \mathrm{kcal} / \mathrm{mol}$ in water solvent at B3LYP/6-31G* and M06/6-31 + G* respectively. Geometry optimizations were also performed at the B3LYP/6-311+G** and M06/6-311 + G** levels of theory.

Calculation of vibrational frequencies has confirmed stationary point with no negative eigen value observed in the force constant matrix.

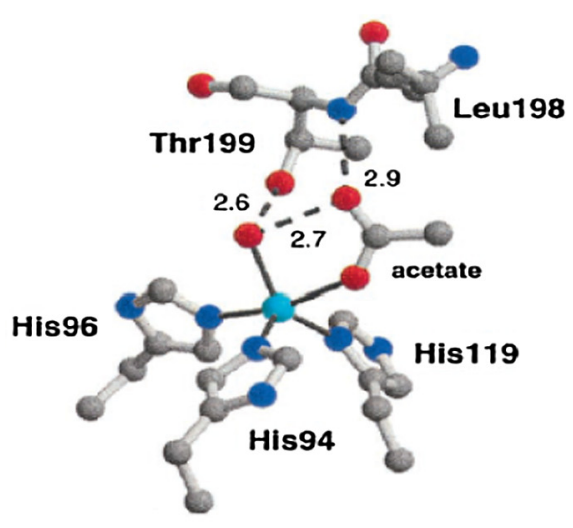

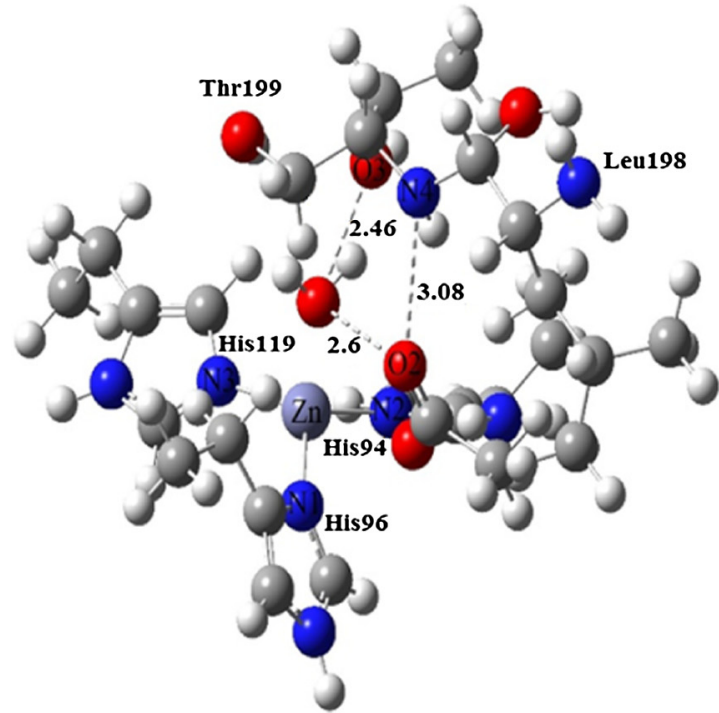

$\mathrm{M} 06 / 6-31+\mathrm{G}^{*}$

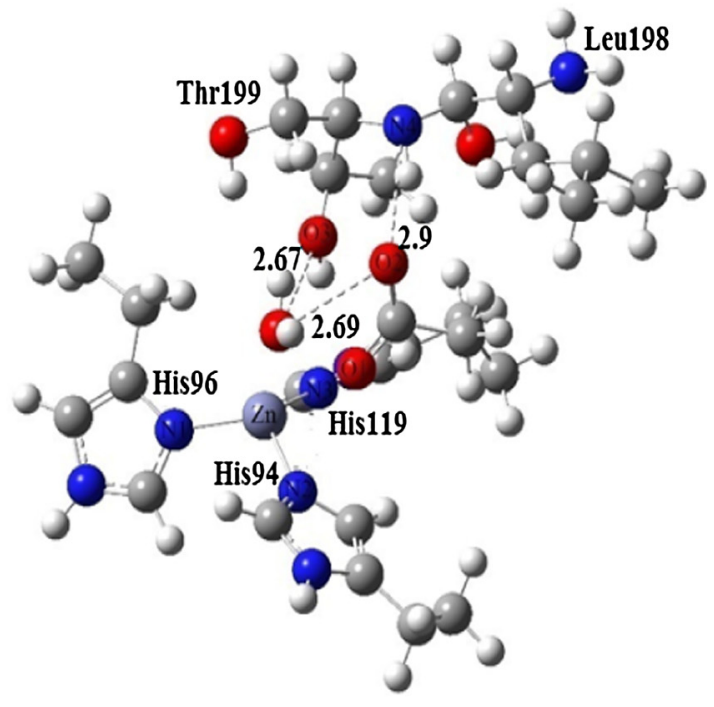

B3LYP/6-31G*

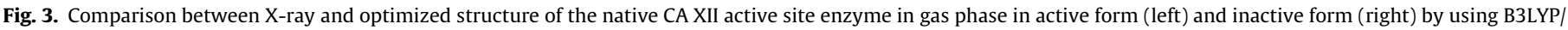
6-31G* and M06/6-31G* methods. The hydrogen bonds with residues Thr 199 and Leu 198 are shown as dashed lines with distances labeled A. 
Table 1

Presentation of some chemical structural details of optimized geometry for the active and inactive forms of CA XII in gas phase by using different methods and comparison with experimental data.

\begin{tabular}{llll}
\hline Bond distance $(\AA)$ & X-ray & M06/6-31+ G $^{*}$ & B3LYP/6-31G* \\
\hline Zn-N1 & 2.1 & 1.97 & 1.98 \\
$\mathrm{Zn}-\mathrm{N} 2$ & 2.0 & 1.96 & 1.97 \\
$\mathrm{Zn}-\mathrm{N} 3$ & 2.1 & 1.97 & 1.98 \\
$\mathrm{Zn}-\mathrm{OH} 2$ & 2.1 & 2.05 & 2.08 \\
$\mathrm{Zn}-\mathrm{O} 1$ & 2.3 & 2.28 & 2.32 \\
$\mathrm{O} 2-\mathrm{N} 4$ & 2.9 & 3.08 & 2.9 \\
O2-OH2 & 2.7 & 2.6 & 2.69 \\
OH2-O3 & 2.6 & 2.46 & 2.67 \\
Standard deviation & & 0.111 & 0.067 \\
\hline
\end{tabular}

\subsection{Geometry optimization and conformational search of inhibitors}

Since the behavior of the chemical compounds, especially carbohydrates, is largely influenced by the overall geometry of the molecule $[40,41]$, the conformational search can be regarded as the important step in this study. By taking a look at the glycosyl coumarins structure in Fig. 2 it is clear that the coumarin ring is almost rigid but the glycosyl moiety can have different conformers. Glycosyl moieties contain several conformational domains such as the exocyclic hydroxymethyl $\left(\mathrm{CH}_{2} \mathrm{OH}\right)$ fragment of monosaccharides and glycosidic linkages with coumarin ring. The conformation about the exocyclic $\mathrm{C} 5-\mathrm{C} 6$ bond is important in the determination of the three-dimensional structures of carbohydrate molecules. In addition, one of the key objectives of conformational studies of oligosaccharides in solution is the estimation of the torsional behavior of their component glycosidic linkages involving a heteroatom; the glycosidic torsion angles $\varphi$ in this case.

In the present report, the orientations about the $\mathrm{C}^{\prime}-\mathrm{C}^{\prime}, \mathrm{C} 5^{\prime}-\mathrm{O} 6^{\prime}$ and $\mathrm{C}^{\prime}-\mathrm{O}$ bonds are described by torsion angles $\left(\omega=\mathrm{O} 5^{\prime}-\mathrm{C}^{\prime}-\mathrm{C}^{\prime}-\mathrm{O} 6^{\prime}\right), \quad\left(\theta=\mathrm{C}^{\prime}-\mathrm{C}^{\prime}-\mathrm{O} 6^{\prime}-\mathrm{H}\right)$ and $\left(\varphi=\mathrm{H} 1^{\prime}-\mathrm{C} 1^{\prime}\right.$ $-\mathrm{O}-\mathrm{C} 7)$ respectively. The $\omega, \theta$ and $\varphi$ torsion angles in galactose, mannose, ribose and glucose coumarin were varied systematically from $0^{\circ}$ to $360^{\circ}$ in $5^{\circ}$ increments by holding three torsion angles at fixed values in the calculations. All other molecular parameters were geometrically optimized. The important results from conformational analysis of these inhibitors around $\omega, \theta$ and $\varphi$ is presented in sections that follow. Analysis of geometries of all inhibitors rotamers indicate that all of them are non-planar, implying that dihedral angle between the coumarin bicycle and sugar moiety is significantly different from zero. The most stable conformer of inhibitors is presented in Fig. 4. The minimization procedure for the all studied inhibitors has been performed at the B3LYP/6-31G* and M06/6$31+G *$ methods yields a non-planar conformation as the more stable one. Table 2 presents the results of conformational search for four studied inhibitors. For example the conformational minimum has been found from B3LYP/6-31G* at $\theta=-175.46$, $\omega=-69.66$ and $\varphi=-180.0$ followed by a relative minimum at $\theta=-173.26, \omega=-71.36$ and $\varphi=-155.0$, with the energy difference of about $12.54 \mathrm{kcal} / \mathrm{mol}$ for galactocoumarin. The potential energy maximum lies at $\theta=-174.78, \omega=-70.21$ and $\varphi=-60.0$ and the

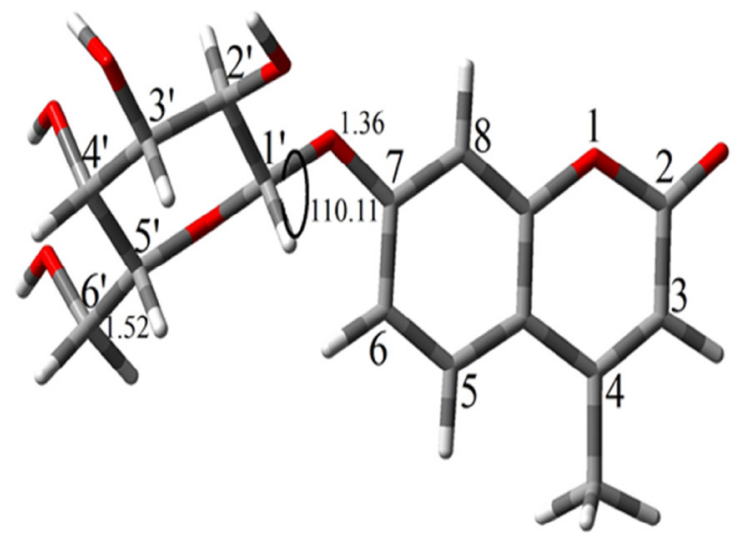

Galactose Coumarin

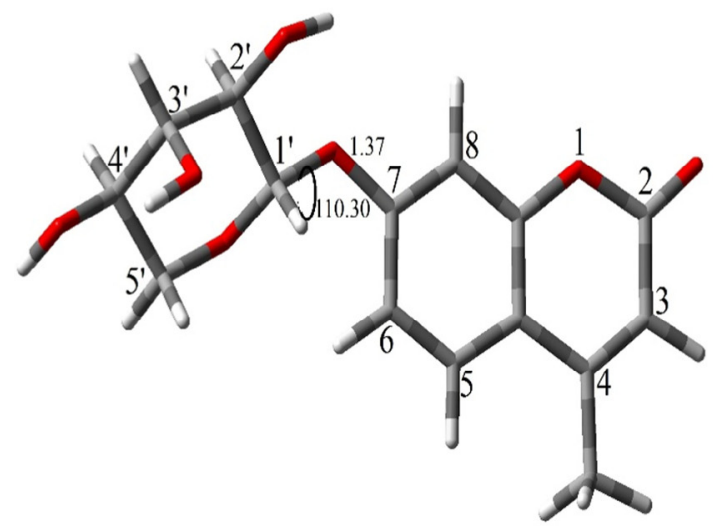

Ribose Coumarin

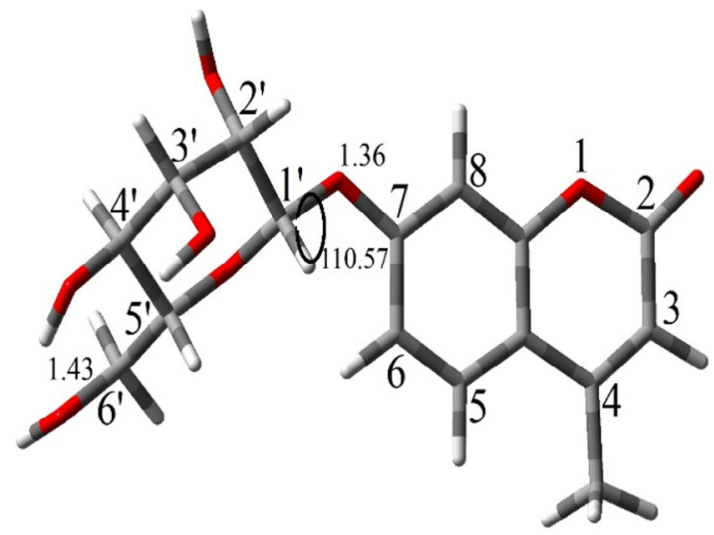

Mannose Coumarin

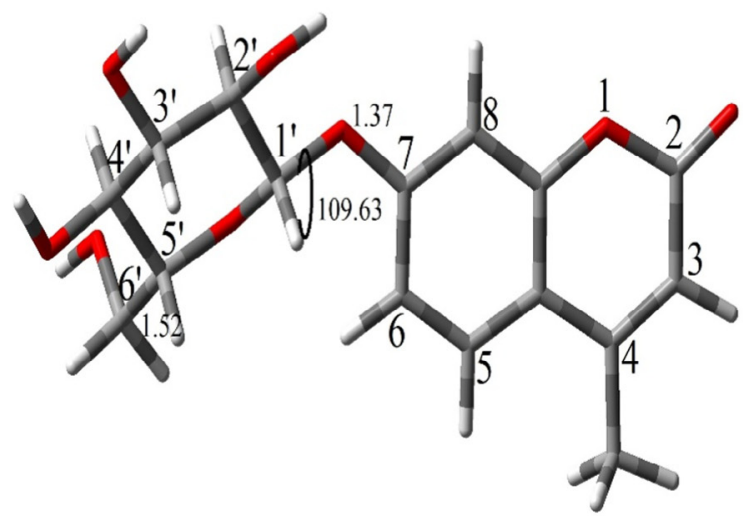

Glucose Coumarin

Fig. 4. Presentation of optimized geometry of galactose, mannose, ribose and glucose coumarin derivatives at the B3lyp/6-31G* method in gas phase. 
Table 2

Presentation of some chemical structural details of optimized most stable conformer of galactose, mannose, ribose and glucose coumarin derivatives.

\begin{tabular}{|c|c|c|c|c|c|c|c|c|}
\hline & \multicolumn{2}{|c|}{ Manose coumarin } & \multicolumn{2}{|c|}{ Ribose coumarin } & \multicolumn{2}{|c|}{ Glucosecoumarin } & \multicolumn{2}{|c|}{ Galactose coumarin } \\
\hline & B3LYP & M06 & B3IYP & M06 & B3LYP & M06 & B3LYP & M06 \\
\hline \multicolumn{9}{|l|}{ Bond Distance $(\AA)$} \\
\hline $\mathrm{C} 5^{\prime}-\mathrm{C}^{\prime}$ & 1.52 & 1.51 & - & - & 1.52 & 1.51 & 1.52 & 1.51 \\
\hline $\mathrm{C} 6^{\prime}-\mathrm{O}^{\prime}$ & 1.43 & 1.42 & - & - & 1.41 & 1.41 & 1.42 & 1.41 \\
\hline $\mathrm{C} 1^{\prime}-\mathrm{O} 1^{\prime}$ & 1.40 & 1.39 & 1.37 & 1.39 & 1.41 & 1.39 & 1.39 & 1.39 \\
\hline $\mathrm{C} 1^{\prime}-\mathrm{O}^{\prime}$ & 1.42 & 1.40 & 1.41 & 1.40 & 1.41 & 1.39 & 1.42 & 1.41 \\
\hline $\mathrm{C} 2-\mathrm{C} 3$ & 1.45 & 1.45 & 1.45 & 1.45 & 1.45 & 1.45 & 1.45 & 1.45 \\
\hline \multicolumn{9}{|l|}{ Bond Angle $\left({ }^{\circ}\right)$} \\
\hline $\mathrm{H} 1^{\prime}-\mathrm{C} 1^{\prime}-\mathrm{O} 1^{\prime}$ & 110.57 & 110.47 & 110.30 & 110.33 & 109.63 & 109.68 & 110.11 & 110.14 \\
\hline $\mathrm{C} 4^{\prime}-\mathrm{O}^{\prime}-\mathrm{H}$ & 106.51 & 108.16 & 108.92 & 108.26 & 105.89 & 107.58 & 107.81 & 109.32 \\
\hline $\mathrm{C} 1^{\prime}-O 5^{\prime}-\mathrm{C}^{\prime}$ & 112.81 & 112.98 & 112.26 & 112.14 & 113.56 & 112.87 & 113.69 & 112.84 \\
\hline $\mathrm{C} 5^{\prime}-\mathrm{C}^{\prime}-\mathrm{O6}^{\prime}$ & 107.64 & 107.86 & - & - & 109.13 & 108.79 & 109.59 & 109.59 \\
\hline $\mathrm{O} 5^{\prime}-\mathrm{C} 1^{\prime}-\mathrm{O} 1^{\prime}$ & 108.33 & 107.70 & 108.36 & 108.38 & 109.04 & 109.08 & 107.87 & 108.05 \\
\hline \multicolumn{9}{|l|}{ Dihedral bond $\left(^{\circ}\right)$} \\
\hline $\mathrm{H} 1^{\prime}-\mathrm{C} 1^{\prime}-\mathrm{O} 1^{\prime}-\mathrm{C} 7$ & 42.83 & 45.20 & 42.39 & 43.50 & 41.71 & 44.04 & 38.65 & 41.39 \\
\hline $\mathrm{C} 5^{\prime}-\mathrm{C}^{\prime}-\mathrm{O6}^{\prime}-\mathrm{H}$ & 168.69 & 175.87 & - & - & -168.01 & -175.99 & -175.46 & 170.07 \\
\hline $\mathrm{O}^{\prime}-\mathrm{C}^{\prime}-\mathrm{C}^{\prime}-\mathrm{O}^{\prime}$ & 178.43 & -179.53 & - & - & -65.14 & -67.35 & -69.66 & -71.04 \\
\hline $\mathrm{O}^{\prime}-\mathrm{C}^{\prime}-\mathrm{C}^{\prime}-\mathrm{O}^{\prime}$ & -170.92 & -170.47 & -173.34 & -174.60 & -175.22 & -175.60 & 62.91 & 61.83 \\
\hline $\mathrm{O} 1^{\prime}-\mathrm{C} 1^{\prime}-\mathrm{O}^{\prime}-\mathrm{C}^{\prime}$ & 178.42 & -179.89 & -177.44 & -178.16 & -178.07 & 179.02 & -177.62 & 179.82 \\
\hline
\end{tabular}

barrier energy between the two minimum is about $31.38 \mathrm{kcal} / \mathrm{mol}$. M06/6-31G* method gives a higher value for the dihedral angles $\theta$, $\omega$ and $\varphi$. Also, the corresponding values for a local minimum and energy barrier are higher than values has been obtained by B3LYP/6-31G* method. It is noticeable that the most stable conformer of all inhibitors re-optimized in water (implicit solvent model) using PCM model to address the electrostatic behavior of water in terms continuous medium. All inhibitors stabilized about $15 \mathrm{kcal} / \mathrm{mol}$; but geometrical parameters of different inhibitors remained almost unchanged. The single point calculations were also carried out with B3LYP/6-311 + G** and M06/6-311 + G** methods. The same trends have been observed when comparing the total energy with each other.

For example the conformational minimum which has been found from B3LYP/6-311+G** at $\theta=-176.86, \omega=-72.26$ and $\varphi=-183.12$ followed by a relative minimum at $\theta=-174.83$, $\omega=-73.47$ and $\varphi=-158.34$, with the energy difference of about $14.00 \mathrm{kcal} / \mathrm{mol}$ for galactocoumarin. The potential energy maximum lies at $\theta=-173.98, \omega=-72.52$ and $\varphi=-62.55$ and the barrier energy between the two minimum is about $33.25 \mathrm{kcal} / \mathrm{mol}$. M06/6-311 + G** method gives a higher value for the dihedral angles $\theta, \omega$ and $\varphi$. Also, the corresponding values for a local minimum and energy barrier are higher than values has been obtained by B3LYP/6-311 + G** method, $35.78 \mathrm{kcal} / \mathrm{mol}$.

\subsection{Interaction between the active site of the native CA XII and inhibitors}

According to previous study on human carbonic anhydrase II, as shown by kinetic and X-ray crystallographic studies, coumarin molecule undergoes hydrolysis under the influence of the zinc hydroxide, which is nucleophilically active form of the enzyme, with generation of substituted 2-hydroxycinamic acids. The initially formed cis-2-hydroxy-cinnamic acid may be stabilized and binds toward the exit of the active site cavity for coumarins substituted with bulky moieties. Alternatively, this intermediate isomerizes to the trans isomer being bound at the same active center region, but with different orientations compared to the cis-2hydroxy-cinnamic acid [18,41]. So according to proposed mechanism in Scheme 1 the most stable conformer of four glycosyl coumarin as the effective inhibitor of CAXII undergo hydrolysis by the zinc bound hydroxide ion which acts as a potent nucleophile. In addition at the presence of water molecule cis-2hydroxy-cinnamic acid intermediate is formed and the active form of the enzyme is converted to inactive form, water bonded to the zinc ion. According to the results of our calculation cis-2hydroxy-cinamic acid cannot bind in the restricted space near the zinc ion while sulfonamides and simple phenols can bind; thus reoriented toward the exit of the active center cavity. In continue a rearrangement of the inhibitor/enzyme adduct occur which leading to provide the trans-2-hydroxy-cinamic acid isomer. Calculated results of four inhibitors indicate that cis- isomer is about 27.99, $0.50,24.04$ and $31.09 \mathrm{kcal} / \mathrm{mol}$ more stable than trans isomer in galacto, mannose, ribose and glucose derivatives respectively. This stability comes from an internal hydrogen bonding between carbonyl oxygen atom and hydroxyl hydrogen atom in cis isomer.

The optimized structures as well as energy stabilities through the inhibition reaction path by four glycosyl coumarin in gas phase are depicted in Fig. 5 and Figs. S1-S3. The energy difference between reactants and products for the total reaction is calculated according to equation 4 and is about 16.53, 105.43, 23.22 and $15.86 \mathrm{kcal} / \mathrm{mol}$ for the cis-isomer of galacto, mannose, ribose and glucose derivatives in gas phase respectively. According to experimental results mannose coumarin is the weakest inhibitor for CAXII enzyme [23]. Interestingly the most positive value of $\Delta \mathrm{E}_{\mathrm{rxn}}$ to belong the mannose derivative that is in good agreement with experimental data.

$\Delta \mathrm{E}=\left(\mathrm{E}_{\mathrm{int}}+\mathrm{E}_{\mathrm{ICA}}\right)-\left(\mathrm{E}_{\mathrm{ACA}}+\mathrm{E}_{\mathrm{inh}}\right)$

$E_{\text {int }}, E_{I C A}, E_{A C A}$ and $E_{\text {inh }}$ refer to calculated total energy of cis or trans intermediate isomer, inactive form of CAXII, active form of CAXII and inhibitor molecule respectively.

To stress the role of sugar moiety in inhibition mechanism we replace the glycosyl moiety with hydrogen atom in coumarin molecule and repeat all the calculation with this new inhibitor. Fig. 6 demonstrate the optimized geometries of cis/trans-cinnamic acid in modeled inhibition mechanism of CA XII by coumarin.

Due to the mechanism of inhibition with this class of compounds, because the hydroxycinnamic acids formed by the active site-mediated hydrolysis of the coumarin prodrug bind in an active center region that is different in all CA isoforms. Furthermore, very minor variations in the original coumarin structure strongly influence the inhibitory power of the compound, because the hydroxycinnamic acids formed after hydrolysis may adopt cis or trans conformations and interact with various amino acid residues at the entrance of the enzyme active site cavity. According to experimental results, coumarin (with inhibition constants $46,800 \mathrm{nM}$ ) is ineffective as human CA XII inhibitor [23], whereas all glycosylated 


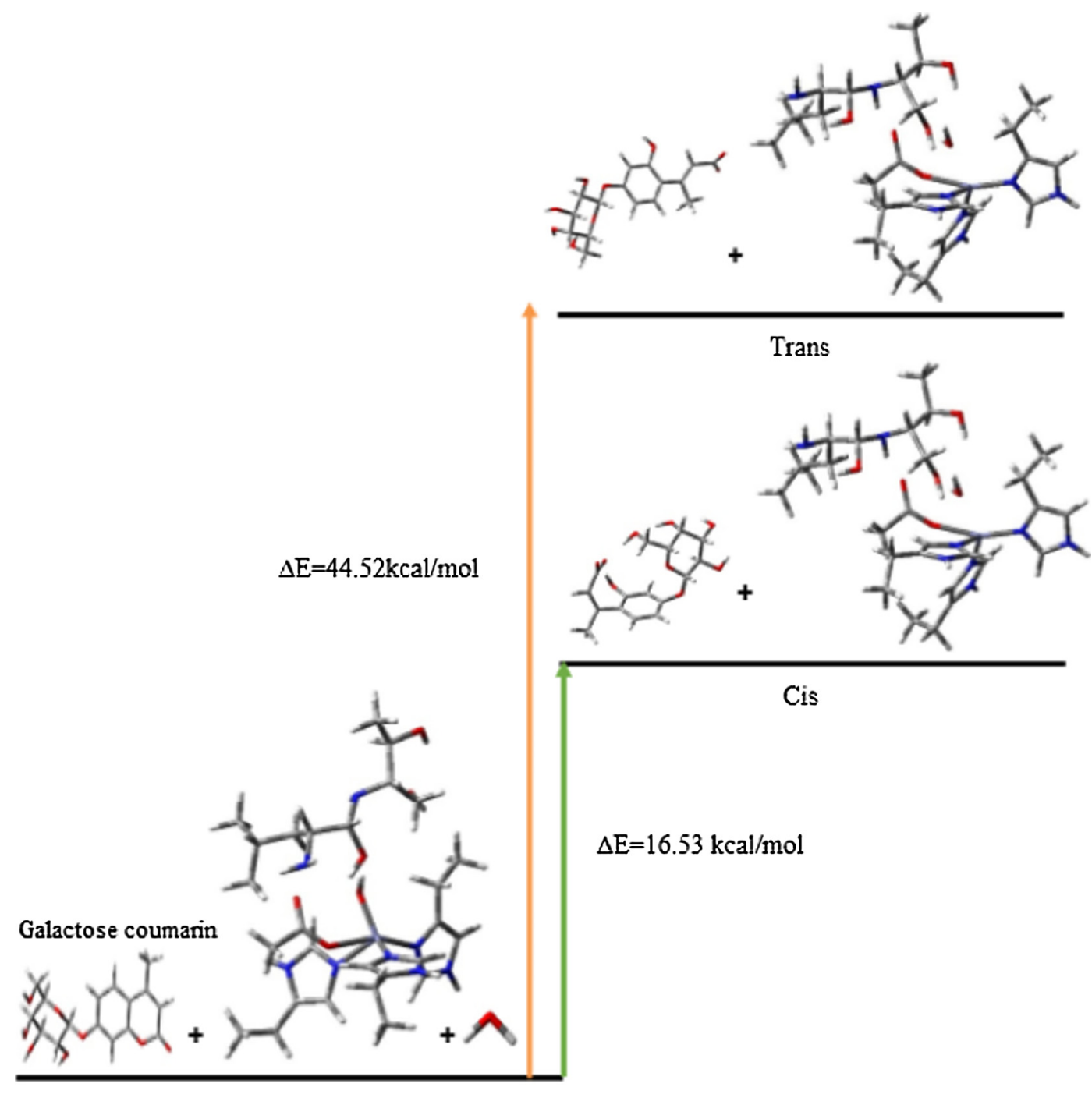

\section{Reactant}

Fig. 5. The optimized geometry of modeled systems in inhibition mechanism of CA XII by galactose coumarin derivative in the presence of one water molecule.

coumarins showed a considerable inhibition of this isoform with inhibition constants in range of 8.5-184 nM. Also just glycosyl coumarin inhibited the growth of primary tumors by the highly aggressive 4T1 syngeneic mouse mammary tumor cells. However, interesting features of the sugar containing carbonic anhydrase are related to the fact that they show good water solubility, and because of the chemical diversity of sugars, a wide range of different molecules could be generated easily.

The energy difference $\left(\Delta \mathrm{E}_{\mathrm{rxn}}\right)$ and all thermodynamic data for the reaction, including enthalpies $\left(\Delta \mathrm{H}^{\circ}{ }_{\mathrm{rxn}}\right)$ and Gibbs energies $\left(\Delta G^{\circ}{ }_{r \times n}\right)$ are calculated for five inhibitors at the two B3LYP/631G* and M06/6-31 + G* level of calculations and presented in Table 3.

In general, the Gibbs energy shows the criterion of the thermodynamically preferred process. Thus according to our calculated results the following two facts can be concluded from analyze of the reported results in Table 3: (I) the following $\Delta \mathrm{G}_{\mathrm{rxn}}$ sequence for the five inhibitors using two B3LYP/6-31G* and M06/6-31 $+\mathrm{G} *$ level is: galacto coumarin $<$ mannose coumarin < ribose coumarin< glucose coumarin< coumarin; so the interaction of the most stable conformer of 7- $\beta$-galactopyranoside-4, -methyl coumarin with most negative value, with CAXII active site should be more favorable thermodynamically than the other inhibitors that is in good agreement with experimental results [23]. Further the energy difference calculated is larger from M06/6-31+G* than B3LYP/6-31G* method. The analysis of the thermodynamic parameters in the solution phase indicate more negative values with the same trends which can caused by solute-solvent electrostatic interactions.

(II) The calculated values by both methods of reaction enthalpy for all inhibitors demonstrate the endothermic interaction between inhibitors and CAXII active site. An interesting observation is that the overall trend observed for the differences (B3LYP and M06) in relative energy values for all inhibitors is repeated when looking at the relative enthalpies and entropies using both functions. It is noticeable that, according to recent experimental study, coumarin is ineffective as hCA XII inhibitor, while the glycosylated coumarins present a considerable inhibition of this isoform with inhibition constants in the range of 8.5-54 nM [23]. Also galactose derivative is the best inhibitor, but effective inhibition was observed for the ribose, mannose and glucose derivatives. In conclusion, according to experimental results and our calculated thermodynamic parameters, clearly confirm that the galactose derivative is the best inhibitor of CA XII isoform and then mannose, 


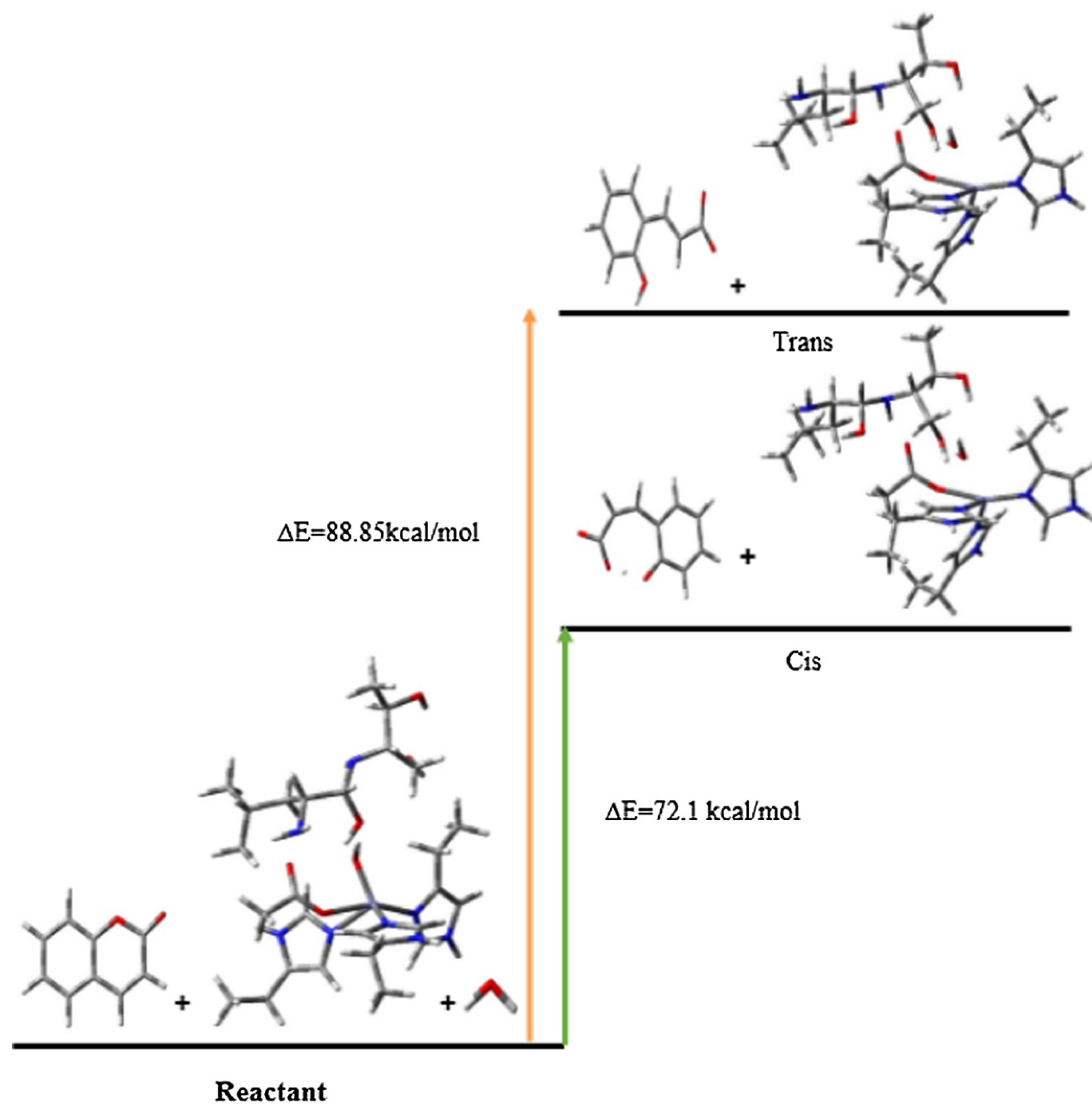

Fig. 6. The optimized geometry of modeled systems in inhibition mechanism of CA XII by coumarin in the presence of one water molecule.

Table 3

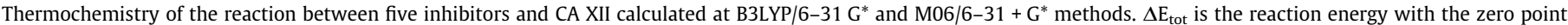
energies included. Note that the conversion energy change values are in $\mathrm{kcal} / \mathrm{mol}$ and the entropy change values are in cal/mol $\mathrm{K}$.

\begin{tabular}{|c|c|c|c|c|c|c|c|c|}
\hline \multirow[t]{2}{*}{ Inhibitor } & \multirow[t]{2}{*}{ Isomer } & \multicolumn{4}{|c|}{ B3LYP/6-31 G* } & \multicolumn{3}{|c|}{$\mathrm{M} 06 / 6-31+\mathrm{G}^{*}$} \\
\hline & & $\Delta E_{r x n}^{t o t}$ & $\Delta \mathrm{H}_{\text {rxn }}^{\circ}$ & $\Delta \mathrm{G}_{\mathrm{rxn}}^{\circ}$ & $\Delta S^{\circ} \mathrm{rxn}$ & $\Delta E_{r x n}^{t o t}$ & $\Delta \mathrm{H}_{\mathrm{rxn}}^{\circ}$ & $\Delta \mathrm{G}_{\mathrm{rxn}}^{\circ}$ \\
\hline \multirow[t]{2}{*}{ Galactos Coumarin } & Cis & 16.53 & 15.95 & 23.75 & -26.18 & 65.45 & 64.87 & 72.67 \\
\hline & Trans & 44.52 & 43.94 & 47.85 & $13.12-$ & 90.74 & 90.16 & 94.06 \\
\hline \multirow[t]{2}{*}{ Glucose Coumarin } & Cis & 16.86 & 16.28 & 24.04 & -26.06 & 67.83 & 67.25 & 74.95 \\
\hline & Trans & 46.95 & 46.37 & 50.27 & -13.08 & 93.62 & 93.04 & 96.94 \\
\hline \multirow[t]{2}{*}{ Ribose Coumarin } & Cis & 23.22 & 22.64 & 30.41 & -26.06 & 74.67 & 74.09 & 81.79 \\
\hline & Trans & 47.26 & 46.68 & 50.58 & -13.08 & 94.56 & 93.98 & 97.88 \\
\hline \multirow[t]{2}{*}{ Mannose Coumarin } & Cis & 105.43 & 104.85 & 112.62 & -26.07 & 168.61 & 168.03 & 175.73 \\
\hline & Trans & 104.93 & 104.35 & 108.25 & -13.09 & 170.93 & 170.35 & 174.25 \\
\hline \multirow[t]{2}{*}{ Coumarin } & Cis & 21.29 & 20.71 & 25.74 & -16.87 & 72.1 & 71.52 & 76.54 \\
\hline & Trans & 43.63 & 43.05 & 46.51 & -11.61 & 88.85 & 88.27 & 91.72 \\
\hline
\end{tabular}

Table 4

Thermochemistry of the reaction between galactose coumarin as the most effective inhibitor and CA XII active site calculated at B3LYP/6-31G* method in the presence of six water molecules. $\Delta \mathrm{E}_{\text {tot }}$ is the reaction energy with the zero point energies included.

\begin{tabular}{llll}
\hline $\mathrm{kcal} \mathrm{mol}^{-1}$ & $\Delta \mathbf{E}_{\mathrm{rxn}}^{\mathrm{tot}}$ & $\Delta \mathrm{H}_{\mathrm{rxn}}$ & $\Delta \mathrm{G}_{\mathrm{rxn}}$ \\
\hline Cis isomer & -47.45 & -48.03 & -40.25 \\
\hline
\end{tabular}

ribose and glucose derivatives are more energetically favorable, while coumarin is not.

Except crystal structure of CA II- coumarin there is not experimental data for other isoform of CA and they still are not fully characterized. So stability energy, thermodynamic data calculation and geometry optimization through the reaction path in CAXII mechanism inhibition can be an interesting achievement. 


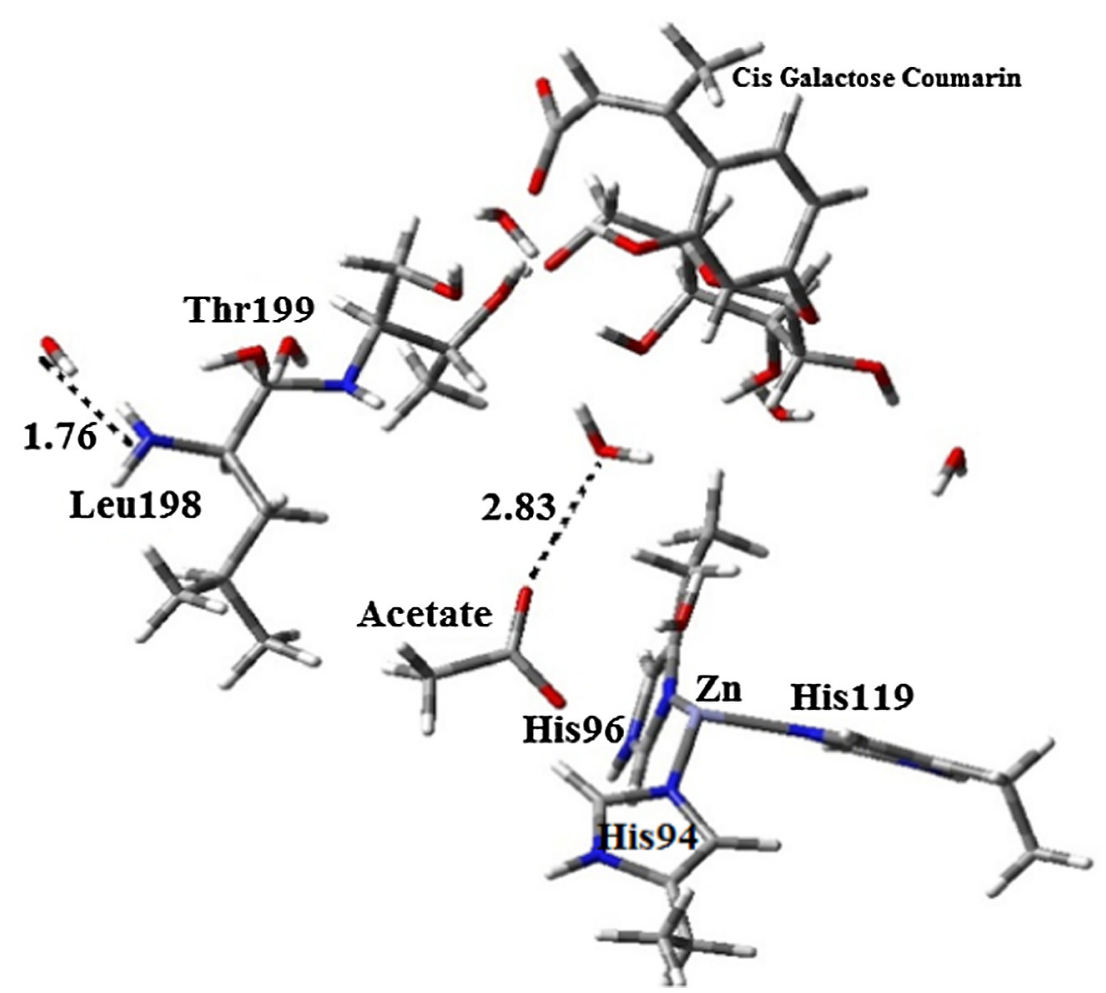

Fig. 7. The optimized geometry of [ICA XII/cis-galacto 2-hydroxy cinnamic acid] in the presence of six water molecules; Bond lengths are given in Å.

\subsection{The explicit solvent effect}

To qualify the role of water solvent in inhibition mechanism of CAXII isoform, we repeat all the calculation for the galactose derivative as the most effective inhibitor using explicit solvent effect. Because of the large number of possible configurations of the water molecules around the lowest possible energy of the studied complex we just consider six water molecules at the first solvation shell around the studied complex near the hydrogen bond donor or acceptor sites. In following all thermodynamic functions have been evaluated and presented in Table 4.

Fig. 7 shows the optimized geometry of [ICAXII/cisgalactocinnamic acid] as well as some geometrical parameters. As the calculated results indicate by adding six water molecules the studied complexes are stabilized about $47.45 \mathrm{kcal} / \mathrm{mol}$.

Moreover results of our calculations indicate the more negative values for the total reaction energy and other thermodynamic functions of the studied inhibitor in the present of water molecule. The negative values of thermodynamic functions for the total reaction show the inhibition of active form of CA XII enzyme by 7galactop inhibitor is exothermic and occurs spontaneously in the presence of water solvent.

\section{Conclusion}

In this study, we presented a thermodynamic study of inhibition mechanism of CA XII by five new inhibitors using two levels of DFT methods. At first the validation of our calculations has been presented by comparison of calculated structural parameters of CA XII active center with X-ray crystallographic data that demonstrate the reliable agreement. In the next step the inhibition mechanism of natural carbonic anhydrase XII by coumarin and four 7galactosyl-coumarin has been investigated extensively from thermodynamic view point. According to our calculated results the hydroxycinnamic acids formed by the active center mediated hydrolysis of the coumarin derivatives in active site region which is different in all CA isoforms and the enzyme active form convert to inactive form. The formed hydroxycinnamic acid after hydrolysis may adopt cis/trans conformations which can interact with around amino acids residues at the entrance of the enzyme active center without binding to the zinc ion. In addition the tendency of interaction of glycosylated coumarin is more than coumarin to inhibit the CA XII thermodynamically that is in good agreement with previous experimental study [23]. Thus the presence of sugar moieties in the coumarin molecule was associated with effective inhibition of CAXII isoform.

In conclusion sugar coumarin as a new class of inhibitors is good candidates for the development of novel anticancer drugs. Therefor tumor CAXII inhibition can lead to fewer side effects compared to classical anticancer drugs in clinical use.

\section{Acknowledgments}

The authors gratefully acknowledge financial support from the Research Council of Alzahra University.

\section{Appendix A. Supplementary material}

Supplementary data associated with this article can be found, in the online version, at http://dx.doi.org/10.1016/j.comptc.2017.08. 034.

\section{References}

[1] C.T. Supuran, Carbonic anhydrases: novel therapeutic applications for inhibitors and activators, Nat. Rev. Drug Discov. 7 (2008) 168-181.

[2] D. Hewett-Emmett, Evolution and distribution of the carbonic anhydrase gene families, in: W.R. Chegwidden, N.D. Carter and Y.H Edwards (Eds.), The Carbonic Anhydrase- New Horizons, Birkhäuser Verlarg, Basel, 2000, 29-78.

[3] S.R. Krungkrai, N. Suraveratum, S. Rochanakij, J. Krungkrai, Characterisation of carbonic anhydrase in Plasmodium falciparum, Int. J. Parasitol. 31 (2001) 661668. 
[4] L.C. Chirica, B. Elleby, B.H. Jonsson, S. Lindskog, The complete sequence, expression in Escherichia coli, purification and some properties of carbonic anhydrase from Neisseria gonorrhoeae, Eur. J. Biochem. 244 (1997) 755-760.

[5] K.S. Smit, J.G. Ferry, Prokaryotic carbonic anhydrase, FEMS Microbiol. Rev. 24 (2000) 335-366.

[6] C.T. Supuran, A. Scozzafava, Carbonic anhydrase inhibitors and their therapeutic potential, Expert Opin. Ther. Pat. 10 (2000) 575-600.

[7] C.T. Supuran, A. Scozzafava, A. Casini, Carbonic anhydrase inhibitors, Med. Res. Rev. 23 (2003) 146-189.

[8] M. Ghiasi, S. Hemati, M. Zahedi, Activation modelling of $\beta$-and $\gamma$-class of carbonic anhydrase with amines and amino acids: proton transfer process within the active site from thermodynamic point of, Comput. Theor. Chem. 1109 (2017) 42-57.

[9] C.T. Supuran, Carbonic anhydrase inhibition with natural products: nove chemotypes and inhibition mechanisms, Mol. Divers. 15 (2011) 305-316.

[10] C.T. Supuran, Carbonic anhydrase inhibitors: an editorial, Expert Opin. Ther. Pat. 23 (2013) 677-679.

[11] C.T. Supuran, A. Maresca, F. Gregáň, Three new aromatic sulfonamide inhibitors of carbonic anhydrases I, II, IV and XII, J. Enzyme Inhib. Med. Chem. 28 (2013) 289-293.

[12] C.T. Supuran, Carbonic anhydrase inhibitors and activators for novel therapeutic applications, Future Med. Chem. 3 (2011) 1165-1180.

[13] A. Scozzafava, C.T. Supuran, J. Conway, Development of Sulfonamide Carbonic Anhydrase Inhibitors, CRC Press, Florida, 2004.

[14] (a) E. Švastová, A. Hulłková, M. Rafajová, M. Zat'ovičová, A. Gibadulinová, A Casini, A. Cecchi, A. Scozzafava, C.T. Supuran, J. Pastorek, S. Pastoreková, Hypoxia activates the capacity of tumor-associated carbonic anhydrase IX to acidify extracellular pH, FEBS Lett. 577 (2004) 439-445;

(b) A. Thiry, J. Dogne, B. Masereel, C.T. Supuran, Targeting tumor-associated carbonic anhydrase IX in cancer therapy, Trends Pharmacol. Sci. 27 (2006) 566-573;

(c) R. Kumar, S. Bua, S. Ram, S. Del Prete, Benzene sulfonamide bearing imidazothiadiazole and thiazolotriazole scaffolds as potent tumor associated human carbonic anhydrase IX and XII inhibitors, Bioorg. Med. Chem. 25 (2017) 1286-1293;

(d) N. Chandak, M. Ceruso, C.T. Supuran, P.K. Sharma, Novel sulfonamide bearing coumarin scaffolds as selective inhibitors of tumor associated carbonic anhydrase isoforms IX and XII, Bioorg. Med. Chem. 24 (2016) 2882-2886.

[15] M. Ghiasi, S. Kamalinahad, M. Arabieh, M. Zahedi, Carbonic anhydrase inhibitors: a quantum mechanical study of interaction between some antiepileptic drugs with active center of carbonic anhydrase enzyme, Comput. Theor. Chem. 992 (2012) 59-69.

[16] M. Ghiasi, S. Kamalinahad, Conformational analysis of topiramate and related anion in the solution and interaction between the most stable conformer of topiramate with active center of carbonic anhydrase enzyme, J. Carbohydr. Chem. 34 (2015) 80-102.

[17] M. Ghiasi, A. Oskouie, H. Saeidian, Dynamic stereochemistry of Topiramate (anticonvulsant drug) in solution: theoretical approaches and experimental validation, Carbohydr. Res. 348 (2012) 47-54

[18] A. Maresca, C. Temperini, H. Vu, N.B. Pham, A. Scozzafava, R.J. Quinn, C.T. Supuran, Non-zinc mediated inhibition of carbonic anhydrases: coumarins are a new class of suicide inhibitors non-zinc mediated inhibition of carbonic anhydrases: coumarins are a new class of suicide inhibitors \#, J. Am. Chem. Soc. 131 (2009) 3057-3062.

[19] A. Maresca, C. Temperini, L. Pochet, B. Masereel, A. Scozzafava, C.T. Supuran, Deciphering the mechanism of carbonic anhydrase inhibition with coumarins and thiocoumarins, J. Med. Chem. 53 (2009) 335-344.

[20] (a) A. Maresca, C.T. Supuran, Coumarins incorporating hydroxy-and chloromoieties selectively inhibit the transmembrane, tumor-associated carbonic anhydrase isoforms IX and XII over the cytosolic ones I and II, Bioorg. Med. Chem. Lett. 20 (2010) 4511-4514;

(b) A. Maresca, A. Scozzafava, C.T. Supuran, 7, 8-Disubstituted-but not 6, 7 disubstituted coumarins selectively inhibit the transmembrane, tumorassociated carbonic anhydrase isoforms IX and XII over the low nanomolar/subnanomolar range, Bioorg. Med. Chem. Lett. 20 (2010) 72557258.

[21] (a) B.L. Wilkinson, L.F. Bornaghi, T.A. Houston, A. Innocenti, C.T. Supuran, S.A. Poulsen, A novel class of carbonic anhydrase inhibitors: glycoconjugate benzene sulfonamides prepared by "click-tailing", J. Med. Chem. 49 (2006) 6539-6548;

(b) B.L. Wilkinson, L.F. Bornaghi, T.A. Houston, A. Innocenti, D. Vullo, C.T. Supuran, S.A. Poulsen, Carbonic anhydrase inhibitors: inhibition of isozymes I, II, and IX with triazole-linked O-glycosides of benzene sulfonamides, J. Med. Chem. 50 (2007) 1651-1657;

(c) B.L. Wilkinson, L.F. Bornaghi, T.A. Houston, A. Innocenti, D. Vullo, C.T. Supuran, S.A. Poulsen, Inhibition of membrane-associated carbonic anhydrase isozymes IX, XII and XIV with a library of glycoconjugate benzenesulfonamides, Bioorg. Med. Chem. Lett. 17 (2007) 987-992.

[22] (a) J.Y. Winum, A. Casini, F. Mincione, M. Starnotti, J.L. Montero, A. Scozzafava, C.T. Supuran, Carbonic anhydrase inhibitors: N-(p-sulfamoylphenyl)- $\alpha-D$ glycopyranosylamines as topically acting antiglaucoma agents in hypertensive rabbits, Bioorg. Med. Chem. Lett. 14 (2004) 225-229;

(b) B.L. Wilkinson, A. Innocenti, D. Vullo, C.T. Supuran, S.A. Poulsen, Inhibition of carbonic anhydrases with glycosyltriazole benzene sulfonamides, J. Med. Chem. 51 (2008) 1945-1953;

(c) M. Lopez, L.F. Bornaghi, A. Innocenti, D. Vullo, S.A. Charman, C.T. Supuran, S.A. Poulsen, Sulfonamide linked neoglycoconjugates- a new class of inhibitors for cancer-associated carbonic anhydrases, J. Med. Chem. 53 (2010) 2913-2926;

(d) M. Singer, M. Lopez, L.F. Bornaghi, A. Innocenti, D. Vullo, C.T. Supuran, S.A. Poulsen, Inhibition of carbonic anhydrase isozymes with benzene sulfonamides incorporating thio, sulfinyl and sulfonyl glycoside moieties, Bioorg. Med. Chem. Lett. 19 (2009) 2273-2276.

[23] N. Touisni, A. Maresca, P.C. McDonald, Y. Lou, A. Scozzafava, S. Dedhar, J.Y. Winum, C.T. Supuran, Glycosyl coumarin carbonic anhydrase IX and XII inhibitors strongly attenuate the growth of primary breast tumors, J. Med. Chem. 54 (2011) 8271-8277.

[24] A.D. Becke, Density-functional thermochemistry. III. The role of exact exchange, J. Chem. Phys. 98 (1993) 5648-5652.

[25] R.G. Parr, Horizons of Quantum Chemistry, Springer, Berlin, 1980.

[26] M. Ghiasi, M. Taheri, M. Zahedi, Thermodynamic study of proton transfer in carbonic anhydrase/activator complex: a quantum mechanical approach, Comput. Theor. Chem. 1022 (2013) 121-129.

[27] M. Ghiasi, S. Kamalinahad, M. Zahedi, Complexation of nanoscale enzyme inhibitor with carbonic anhydrase active center: a quantum mechanical approach, J. Struct. Chem. 55 (2014) 1574-1586.

[28] Y. Zhao, D. Truhlar, The M06 suite of density functionals for main group thermochemistry, thermochemical kinetics, noncovalent interactions, excited states, and transition elements: two new functionals and systematic testing of four M06-class functionals and 12 other functionals, Theor. Chem. Acc. 120 (2008) 215-241.

[29] V. Barone, M. Cossi, J. Tomasi, Geometry optimization of molecular structures in solution by the polarizable continuum model, J. Comput. Chem. 19 (1998) 404-417.

[30] S. Miertuš, E. Scrocco, J. Tomasi, Electrostatic interaction of a solute with a continuum. A direct utilization of $\mathrm{AB}$ initio molecular potentials for the prevision of solvent effects, Chem. Phys. 55 (1981) 117-129.

[31] S. Miertuš, J. Tomasi, Approximate evaluations of the electrostatic free energy and internal energy changes in solution processes, Chem. Phys. 65 (1982) 239245.

[32] J.L. Pascual-Ahuir, E. Silla, J. Tomasi, Electrostatic interaction of a solute with a continuum. Improved description of the cavity and of the surface cavity bound charge distribution, J. Comput. Chem. 8 (1987) 778-787.

[33] M.J. Frisch, G.W. Trucks, H.B. Schlegel, G.E. Scuseria, M.A. Robb, J.R. Cheeseman, J.J.A. Montgomery, T. Vreven, K.N. Kudin, J.C. Burant, J.M. Millam, S.S. Iyengar, J. Tomasi, V. Barone, B. Mennucci, M. Cossi, G. Scalmani, N. Rega, G.A. Petersson, H. Nakatsuji, M. Hada, M. Ehara, K. Toyota, R. Fukuda, J. Hasegawa, M. Ishida, T. Nakajima, Y. Honda, O. Kitao, H. Nakai, M. Klene, X. Li, J.E. Knox, H.P. Hratchian, J.B. Cross, V. Bakken, C. Adamo, J. Jaramillo, R. Gomperts, R.E. Stratmann, O. Yazyev, A.J. Austin, R. Cammi, C. Pomelli, J.W. Ochterski, P.Y. Ayala, K. Morokuma, G.A. Voth, P. Salvador, J.J. Dannenberg, V.G. Zakrzewski, S. Dapprich, A.D. Daniels, M.C. Strain, O. Farkas, D.K. Malick, A.D. Rabuck, K. Raghavachari, J.B. Foresman, J.V. Ortiz, Q. Cui, A.G. Baboul, S. Clifford, J. Cioslowski, B.B. Stefanov, G. Liu, A. Liashenko, P. Piskorz, I. Komaromi, R.L. Martin, D.J. Fox, T. Keith, M.A. Al-Laham, C.Y. Peng, A. Nanayakkara, M. Challacombe, P.M.W. Gill, B. Johnson, W. Chen, M.W. Wong, C. Gonzalez, J.A. Pople, Gaussian 09, Revision A.08 Inc. Wallingford, CT, 2009.

[34] R.D. Dennington, T.A. Keith, J.M. Millam, GaussView 5.0. 8, Gaussian Inc. 2008

[35] M. Navarrete, C. Rangel, J.C. Corchado, J. Espinosa-Garcia, Trapping of the $\mathrm{OH}$ radical by $\alpha$-tocopherol: a theoretical study, J. Phys. Chem. A. 109 (2005) 4777-4784.

[36] A.K. Chandra, T. Uchimaru, The $\mathrm{OH}$ bond dissociation energies of substituted phenols and proton affinities of substituted phenoxide ions: a DFT study, Int. J. Mol. Sci. 3 (2002) 407-422.

[37] H.Y. Zhang, H.F. Ji, S-H proton dissociation enthalpies of thiophenolic cation radicals: a DFT study, J. Mol. Struct. Theochem. 663 (2003) 167-174.

[38] D.A. Whittington, A. Waheed, B. Ulmasov, G.N. Shah, J.H. Grubb, W.S. Sly, D.W. Christianson, Crystal structure of the dimeric extracellular domain of human carbonic anhydrase XII, a bitopic membrane protein overexpressed in certain cancer tumor cells, Proc. Natl. Acad. Sci. U. S. A. 98 (2001) 9545-9550.

[39] M. Tafazzoli, M. Ghiasi, New karplus equations for ${ }^{2} \mathrm{~J}_{\mathrm{HH}},{ }^{3} \mathrm{~J}_{\mathrm{HH}},{ }^{2} \mathrm{~J}_{\mathrm{CH}},{ }^{3} \mathrm{~J}_{\mathrm{CH}},{ }^{3} \mathrm{~J}_{\mathrm{COCH}}$, ${ }^{3} \mathrm{~J}_{\mathrm{CSCH}}$ and ${ }^{3} \mathrm{~J}_{\mathrm{CCCH}}$ in some aldohexopyranoside derivatives, as determined using NMR spectroscopy and density functional theory calculations, Carbohydr. Res. 342 (2007) 2086-2096.

[40] M. Tafazzoli, M. Ghiasi, Conformational study of anomeric center in some carbohydrate derivatives, Comput. Theor. Chem. 814 (2007) 127-130.

[41] C. Temperini, A. Innocenti, A. Scozzafava, S. Parkkila, C.T. Supuran, The coumarin-binding site in carbonic anhydrase accommodates structurally diverse inhibitors: the antiepileptic lacosamide as an example and lead molecule for novel classes of carbonic anhydrase inhibitors, J. Med. Chem. 53 (2009) 850-854 